\title{
Modifying the dissolved-in-water type natural gas field simulation model based on the distribution of estimated Young's modulus for the Kujukuri region, Japan
}

\author{
T. Nakagawa ${ }^{1}$, R. Matsuyama ${ }^{1}$, M. Adachi ${ }^{2}$,a, S. Kuroshima ${ }^{3}$, T. Ogatsu ${ }^{1}$, and R. Adachi ${ }^{2}$ \\ ${ }^{1}$ Kanto Natural Gas Development Co., Ltd., Mobara, Chiba, Japan \\ ${ }^{2}$ INPEX Corporation, Nigata, Japan \\ ${ }^{3}$ Godo Shigen Co., Ltd., Chiba Office, Chiba, Japan \\ ${ }^{a}$ now at: Teikoku Oil \& Gas Venezuela, CA, Venezuela
}

Correspondence to: T. Nakagawa (t.nakagawa@k-and-o-energy.co.jp)

Published: 12 November 2015

\begin{abstract}
A simulation model, which covers the part of Southern-Kanto natural gas field in Chiba prefecture, was developed to perform studies and make predictions of land subsidence. However, because large differences between simulated and measured subsidence occurred in the northern modeled area of the gas field, the model was modified with an estimated Young's modulus distribution. This distribution was estimated by the yield value distribution and the correlation of yield value with Young's modulus. Consequently, the simulated subsidence in the north area was improved to some extent.
\end{abstract}

\section{Introduction}

The Southern-Kanto natural gas field is the largest dissolvedin-water type gas field in Japan. The natural gas is mainly produced in the Kujukuri region of Chiba prefecture for about 80 years. There is a high concentration of iodine found in the formation water. The Southern-Kanto natural gas field contributes about $30 \%$ of total world iodine production. Therefore iodine is a precious resource for a resource-poor country like Japan.

The reservoir of the Southern-Kanto natural gas field is called the Kazusa group. The Kazusa group consists of alternate layers of mudstone and unconsolidated sand. The strata are several decimeters to several tens of meters thick. The alternate layers of the Kazusa group form a homocline with an inclination of approximately $5^{\circ}$.

Almost gas wells are vertical and are completed with perforated-pipe of several hundred meters in length. Natural gas and formation water are produced with a submersible pump or by gas lift from many strata simultaneously.

Land subsidence in this area was first observed in the late 1960s. The eight companies producing natural gas in this area have been making efforts to control land subsidence in accordance with the subsidence prevention agreement concluded with the local government. Although land subsidence in recent years has been reduced in many areas, subsidence of more than $10 \mathrm{~mm}$ per annum is still observed in some places. The eight companies currently operating in this area are addressing environmental problems including land subsidence through the Environment Committee of the Japan Natural Gas Association Keiyo Natural Gas Association (hereinafter referred to as the Environment Committee).

\section{Simulation model}

A simulation model, which covers the part of SouthernKanto natural gas field in Chiba prefecture, was developed by the Environment Committee to perform studies and make predictions of land subsidence. The JARAS/3-D simulator was used for this simulation model. This simulator was developed by the former Japan National Oil Corporation and the eight companies (Nakagawa et al., 2010).

The effective stress of this reservoir until present has not yet reached the critical yield criterion that differentiates elastic and plastic deformation of the reservoir based on the re- 


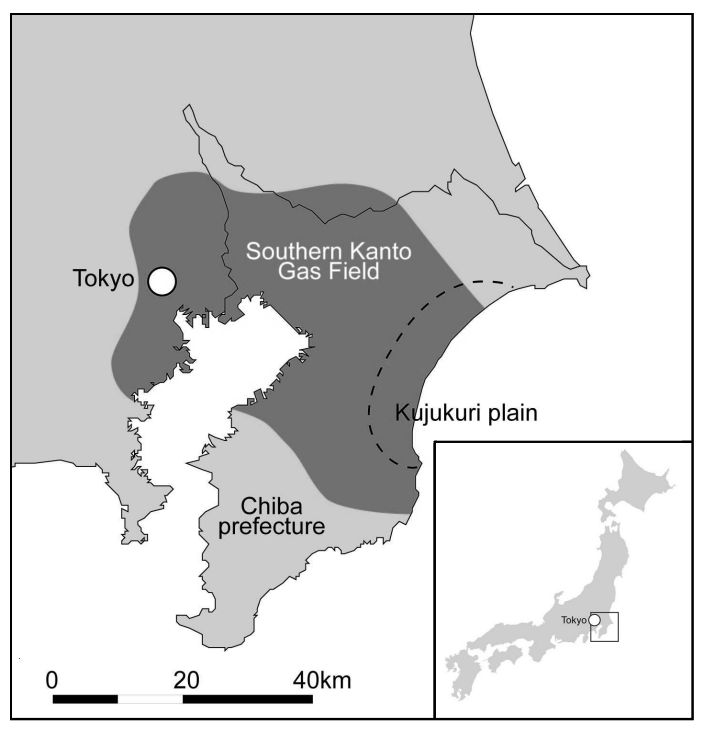

Figure 1. The Southern-Kanto natural gas field.

sults of consolidation tests. Therefore only elastic deformation was simulated in this model. The model area (Fig. 2) is about $67 \mathrm{~km}(\mathrm{~N}-\mathrm{S}$ direction) by about $48 \mathrm{~km}(\mathrm{E}-\mathrm{W}$ direction).

The model was calibrated through history matching of simulated and measured pore fluid pressures. Simulated land subsidence using the calibrated model was compared to subsidence measured using leveling data. Large differences between simulated and measured land subsidence occurred in the northern portion of the modeled area.

\section{Improved subsidence simulation using the estimated Young's modulus distribution}

Values of Young's modulus specified in the model were suspected as one of causes of the large differences between simulated and measured subsidence. Values of Young's modulus were determined from triaxial compression tests on cores collected only from the southern portion of model area (Fig. 3a) which indicated that the values depended on depth. The depth trend of Young's modulus was specified in the model uniformly throughout the modeled area. In order to improve estimates of Young's modulus in the northern portion of the modeled area, the yield value data from consolidation tests of cores collected throughout the modeled area (Fig. 3a) were used to estimate Young's modulus in the northern area.

First, the correlation of yield value with Young's modulus was determined for cores collected in the southern modeled area (Fig. 3b). Several of cores collected at each different depth on same coring point in Fig. 3a. Therefore it appears there are more points shown in Fig. $3 b$ than the coring points for triaxial compression tests shown in Fig. 3a. Then,
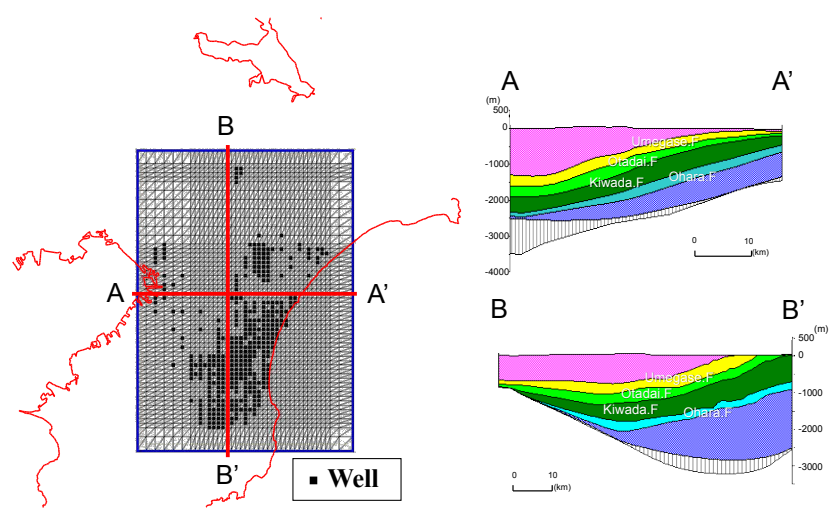

Figure 2. Simulation model.

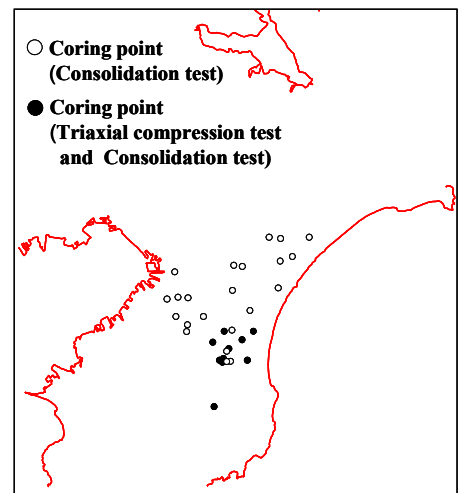

(a)

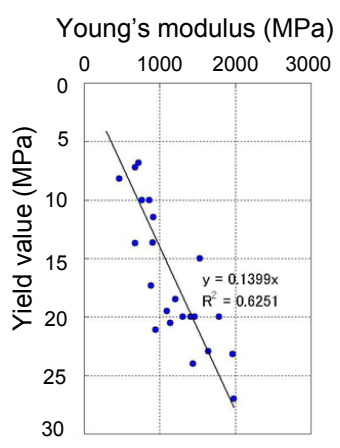

(b)
Figure 3. Core data used for estimation Young's modulus distribution: (a) coring point of consolidation tests and triaxial compression test and (b) correlation between yield value and Young's modulus.

estimates of Young's modulus for the northern modeled area were made based on the yield values for cores collected in the northern modeled area and the correlation of yield value with Young's modulus determined for cores tested in the southern modeled area (Fig. 4). The results show that the depth dependent Young's modulus values decrease along a northwest direction. The simulation model was modified with this estimated Young's modulus distribution. Consequently, simulated subsidence in the north area was improved to some extent (Fig. 5).

\section{Conclusions}

Conclusions are as follows:

a. The gas field simulation model created by the Environment Committee showed large differences between simulated and measured land subsidence in the northern area of the simulation model.

b. A new distribution of Young's modulus was determined in an attempt to resolve the discrepancy between sim- 


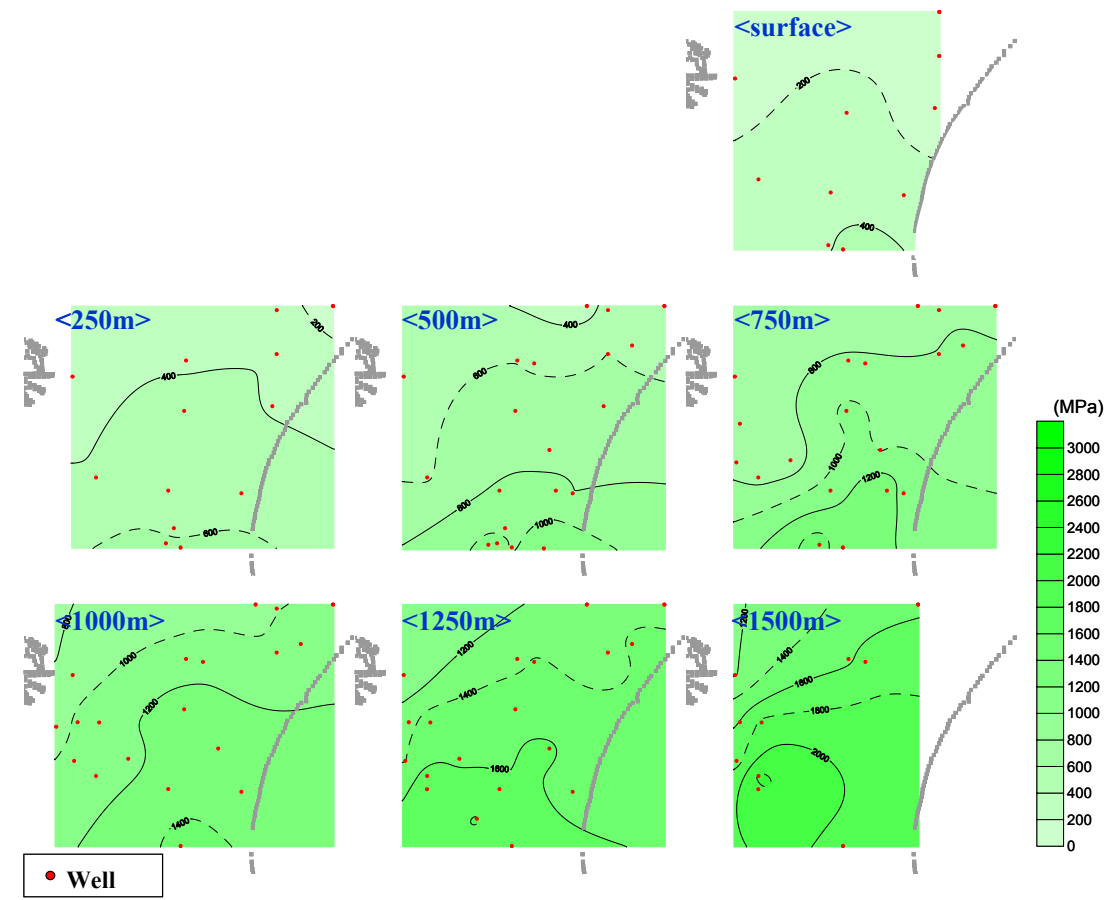

Figure 4. Estimated Young's modulus in each $250 \mathrm{~m}$ depth interval of reservoir.

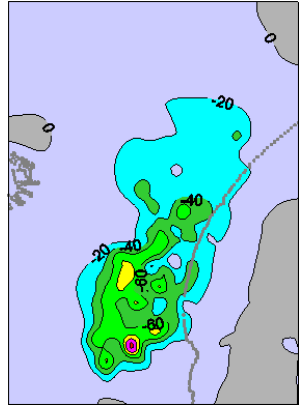

(a)

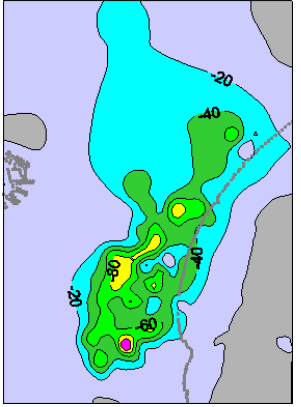

(b)

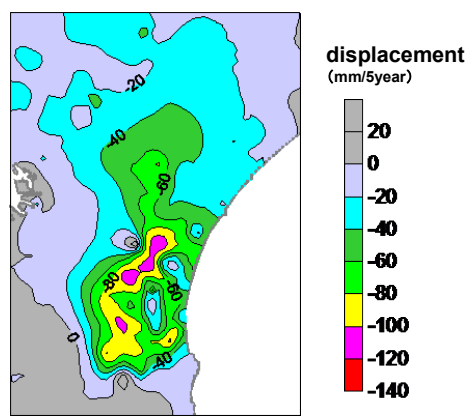

(c)

Figure 5. Comparison simulated and measured land subsidence from 1990 to 1994, (a) simulated result without modified Young's modulus distribution, (b) simulated result with modified Young's modulus distribution and (c) Leveling result.

ulated and measured subsidence. The revised Young's modulus distribution was estimated using the distribution of yield value determined from consolidation tests on cores collected throughout the modeled area and the correlation of yield value and Young's modulus determined from triaxial compression tests on cores collected in the southern area of the modeled area. The results show that the revised depth dependent Young's modulus values decrease along a north-west direction.

c. The simulation model was modified with the estimated Young's modulus distribution. Consequently, simulated subsidence in the northern modeled area was improved to some extent.
Acknowledgements. The content of this paper is based on the results of a joint study conducted by the Environment Committee of the Japan Natural Gas Association and Keiyo Natural Gas Association. The Environment Committee kindly permitted us to publish their study results in this paper.

\section{References}

Nakagawa, T., Suzuki, I., Nojo, M., Ogatsu, T., and Higuchi, T.: Introduction of the JARAS/3D simulator for natural gas dissolved in water, Land subsidence, Associated Hazards and the Role of Natural Resources Development, IAHS Publ., 339, 140-143, 2010. 